\title{
BROOKHEVEN
}

NATIONAL LABORATORY

BNL-101320-2013-IR

\section{Snapshot of NGSI Human Capital Development and Future Roadmap}

\author{
Melissa Scholz, Shaheen Dewji, Sarah Poe, Lauren Finklea
}

July 2013

\author{
Nonproliferation and National Security \\ Brookhaven National Laboratory \\ U.S. Department of Energy \\ National Nuclear Security Administration
}

Notice: This manuscript has been authored by employees of Brookhaven Science Associates, LLC under Contract No. DE-AC02-98CH10886 with the U.S. Department of Energy. The publisher by accepting the manuscript for publication acknowledges that the United States Government retains a non-exclusive, paid-up, irrevocable world-wide license to publish or reproduce the published form of this manuscript, or allow others to do so, for United States Government purposes. 


\section{DISCLAIMER}

This report was prepared as an account of work sponsored by an agency of the United States Government. Neither the United States Government nor any agency thereof, nor any of their employees, nor any of their contractors, subcontractors, or their employees, makes any warranty, express or implied, or assumes any legal liability or responsibility for the accuracy, completeness, or any third party's use or the results of such use of any information, apparatus, product, or process disclosed, or represents that its use would not infringe privately owned rights. Reference herein to any specific commercial product, process, or service by trade name, trademark, manufacturer, or otherwise, does not necessarily constitute or imply its endorsement, recommendation, or favoring by the United States Government or any agency thereof or its contractors or subcontractors. The views and opinions of authors expressed herein do not necessarily state or reflect those of the United States Government or any agency thereof. 


\title{
2013 Snapshot of NGSI Human Capital Development and Future Roadmap Melissa Scholz' ${ }^{1}$, Shaheen Dewji ${ }^{2}$, Sarah Poe ${ }^{3}$, Lauren Finklea ${ }^{2}$
}

\author{
1 U.S. National Nuclear Security Administration, \\ 2 Oak Ridge National Laboratory, \\ 3 Brookhaven National Laboratory \\ Melissa.Scholz@nnsa.doe.gov
}

\begin{abstract}
Since its creation in 2008, the Human Capital Development (HCD) subprogram of NNSA's Next Generation Safeguards Initiative (NGSI) has been striving to develop sustainable academic and technical programs that support the recruitment, education, training, and retention of the next generation of international safeguards professionals. This effort endeavors to develop additional human resources to equip a new cadre of safeguards and nonproliferation experts to meet the needs of both the United States and the International Atomic Energy Agency (IAEA) for decades to come, specifically in response to data that indicates that $82 \%$ of the 2009 safeguards experts at U.S. Laboratories will have left the workforce within 15 years. This paper provides an update on the status of the program since its last presentation at the INMM Annual Meeting in 2010, including strengthened and integrated efforts in the areas of graduate and post-doctoral fellowships, young and mid-career professional support, additional short safeguards coursework, and expanded university engagement. In particular, the paper will cover the NGSI Human Capital Roadmap currently being developed in safeguards and nonproliferation education, training, and knowledge retention. The NGSI Human Capital Roadmap aims to provide additional data points and metrics on where the human capital demand lies, which disciplines and skill sets are needed in the field, and how NGSI HCD can best address these issues to meet future demand.
\end{abstract}

\section{Introduction}

The workforce supporting international safeguards faces many of the same demographic challenges confronting the nuclear workforce as a whole, with high percentages of retirees expected in the coming years. This includes the predicted retirement of an estimated $50 \%$ of International Atomic Energy Agency (IAEA) safeguards staff between 2008 and 2013 and a comparable loss of safeguards experts at the U.S. national laboratories between 2009 and 2019.i Constrained budgets, demanding high-profile investigations, increases in the quantity of nuclear material under IAEA safeguards, and transitions in IAEA safeguards approaches have put the international safeguards system under more strain today than at any point in its history. ${ }^{i i}$

The National Nuclear Security Administration (NNSA) recognizes the urgent need to address safeguards and nonproliferation human capital challenges. In 2006-2007, NNSA launched a comprehensive year-long study to examine the broad range of challenges that the international safeguards system must confront over the succeeding 25 years. The primary recommendation of this study was for the establishment of a Next Generation Safeguards Initiative (NGSI) to strengthen safeguards policies and institutions, coordinate U.S. safeguards research and development, and revitalize the U.S. safeguards technology and human capital base. In particular, the study found that "the safeguards human capital base in the United States - the pool of expertise available to develop, design, implement, and support the approaches, methods, and technologies necessary to respond to future 
safeguards challenges - must be revitalized and expanded to ensure a seamless succession from the current generation of experts, many of whom will soon retire, to a new generation of talent with capabilities that cover the full spectrum of safeguards-relevant disciplines." ${ }^{\text {iii }}$

Since the launch of NGSI in late 2007, Human Capital Development (HCD) has been a key subprogram of the initiative, striving to cultivate sustainable academic and technical programs that support the recruitment, education, training, and retention of the next generation of international safeguards professionals.

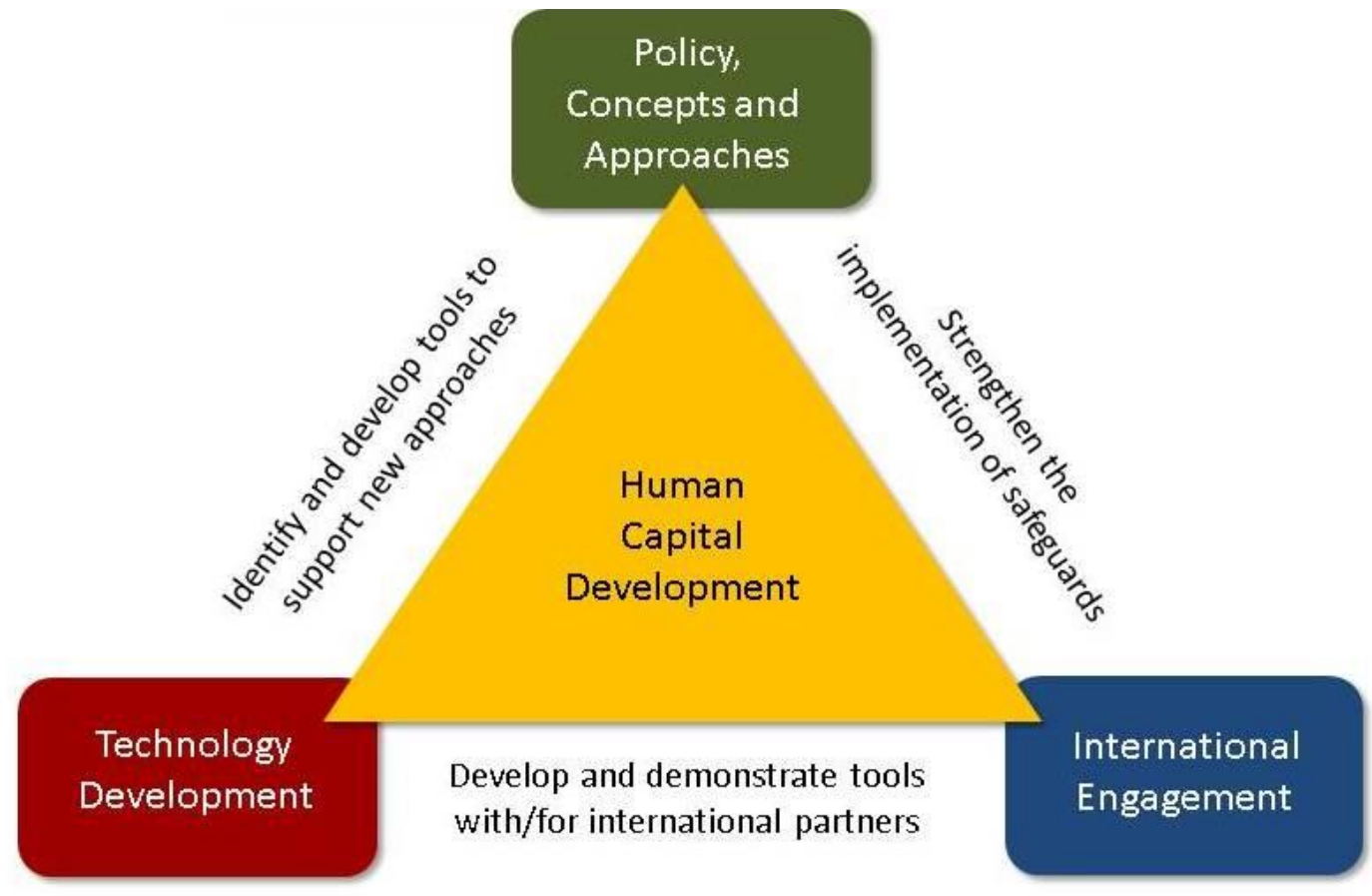

Figure 1: Next Generation Safeguards Initiative (NGSI) elements

NGSI HCD employs a multi-faceted and multi-pronged approach to the human capital challenge. This has included a study to determine current and future safeguards workforce and skills requirements at the U.S. national laboratories; university engagement; safeguards internships; short courses; professional development; and a new project to capture institutional knowledge in the safeguards field. Each of these is discussed in turn below.

\section{Workforce Study}

In 2009, NGSI HCD initiated an empirical workforce staffing study to identify gaps in the safeguards professionals field. This study underpins the initiative; without a clear baseline of safeguards capabilities and gaps, it would be difficult to have any confidence in future projections. The staffing study assessed the anticipated human resource needs in the U.S. national lab complex over a fifteen year period to support international safeguards objectives. It addressed the size of the workforce needed, skill sets, educational background, and work experience. Completed in the second half of 2010, it projected the expected 
impact of demographic trends given various scenarios for the growth of nuclear power, as well as programmatic budgets and the evolution of international safeguards towards a state-level approach. The findings from this initial study estimated that less than $20 \%$ of the international safeguards specialists in the U.S. workforce were 44 years of age or younger, and anticipated that over $80 \%$ of the international safeguards specialists at the national laboratories will be retired or otherwise resigned by 2024 . These striking numbers underscore the importance of recruiting and retaining a new cadre of international safeguards professionals.

In 2013, NGSI HCD has initiated a second iteration of this foundational study. Like the original study, this follow-up will provide an empirical data set on the size, occupations, work activities, educational background, age, and core capabilities of the scientist and engineer workforce supporting safeguards projects across the laboratory complex. From this data set, NGSI hopes to assess how the age trends and estimated attrition rates have changed over the course of the past few years, in light of an aging workforce and significant NGSI investment in the educating and training of a new generation of professionals.

\section{University Engagement}

Building university-laboratory partnerships has been a critical component of NGSI HCD since its launch. Efforts have centered primarily on strong engineering schools within geographic proximity to a national laboratory, and have involved developing and introducing safeguards and nonproliferation lectures and curricula into engineering coursework. A key component to this endeavor has been identifying faculty champions and ensuring a multi- and inter-disciplinary approach. For example, a number of courses developed through NGSI have cross-listed in both the engineering/science and policy schools at respective universities.

In 2013, NGSI HCD expects to sponsor more than two dozen guest lectures by laboratory safeguards specialists to undergraduate and graduate students across the country. Curriculum development has taken place in partnership with the University of Florida, the Georgia Institute of Technology, Idaho State University, University of Michigan, University of New Mexico, North Carolina State University, Oregon State University, Penn State University, University of South Carolina, Stony Brook University, University of Tennessee, University of Washington, and Washington State University. Eleven of these will hold a NGSI HCD sponsored course for academic credit in 2013.

Beginning in 2010, NGSI HCD began sponsoring a nationally competitive graduate fellowship program that targets graduate students in nuclear engineering and related technical disciplines specializing in nonproliferation and international safeguards. These Nuclear Nonproliferation and International Safeguards (NNIS) fellowships cover one to four years of graduate study, and require practicums and thesis or dissertation work performed in areas related to international safeguards. The program pays student tuition, administers monthly stipends, and coordinates national laboratory-based summer practicums. In 2013, the program expanded beyond U.S. national labs, and in June, one NNIS fellow completed his practicum at the European Commission's Joint Research Centre in Ispra, Italy - the first practicum to be completed with an international partner. 
Currently, students from twelve universities are eligible to apply for the NNIS fellowship: Clemson University, University of California-Berkeley, the Georgia Institute of Technology, University of Illinois, the Massachusetts Institute of Technology, University of Michigan, Missouri University of Science and Technology, Missouri University, North Carolina State University, Oregon State University, Penn State University, University of Tennessee, Texas A\&M University, and University of Texas. Schools become eligible through an application process in which they confirm interdisciplinary course offerings that address both the technical and policy aspects of nonproliferation.

In April 2013, the NGSI HCD-sponsored, Brookhaven National Laboratory-produced textbook titled Deterring Nuclear Nonproliferation: The Importance of IAEA Safeguards was published. The book is designed to be a primer for both technical and policy students; previously, in 2012, draft copies of the book were first used in a nonproliferation nuclear engineering course at Texas $\mathrm{A} \& \mathrm{M}$ and a nonproliferation policy course at the University of Washington as pilot cases. The book can be downloaded free of charge at http://www.bnl.gov/gars/NNS/IAEAtextbook.php.

\section{Internship Opportunities}

NGSI offers students the opportunity to pursue summer safeguards internships at U.S. national laboratory locations. Interns are matched with mentors and are given the opportunity to work directly on NGSI safeguards projects. Most interns support safeguards technology development tasks. In its inaugural year (2008), the program drew 50 students from around the country. In 2009, this number more than doubled, with 110 internsrepresenting more than forty U.S. and foreign universities-participating in internships within the national laboratory complex. From 2010-2012, NGSI sponsored 50-100 internships per year, while also expanding internships to include fall or spring semesters; interns in these years represented more than 100 universities. Roughly a third of all interns have come from nuclear engineering backgrounds, and a tenth each from international relations and other (non-nuclear) engineering degree programs. Other educational backgrounds include: radiochemistry, computer science, health physics, social science, and nuclear physics.

In the past, NGSI has been able to sponsor intern participation at the annual Institute of Nuclear Materials Management (INMM) meeting, as well as the JD Williams Student Award given for the best papers and posters at the annual meeting. However, because of restrictions on conference attendance, NGSI was not able to support either effort in 2013. In 2013, the sequester and budget difficulties have also shrunk the internship program to less than forty students, but it is expected that internships will continue to be a core element of the NGSI HCD effort. Notably, a third of interns return for multiple internships, and more than $80 \%$ of interns also participate in an NGSI short course. Internship offerings have been critical to establishing a continuous pipeline of qualified new professionals in the safeguards field. In particular for students who become interested in the work through the NGSI university engagement effort, internships offer the opportunity to gain hands-on knowledge working at a national lab.

\section{Short Courses}


Short courses are a staple of the HCD program's outreach to students and young professionals. These courses - one to three weeks in length - are hosted at the national laboratories or nearby universities. Some courses are focused on technical aspects and technical university students such as engineers and scientists, while others are geared towards nonproliferation policy majors and political/social scientists. Most participants are graduate students or post-Masters/post-Doctoral professionals.

The following NGSI HCD courses took place in the first half of 2013: International Safeguards Policy and Information Analysis (1 week at Lawrence Livermore National Laboratory, in conjunction with the Monterey Institute of International Studies); Nuclear Nonproliferation, Safeguards and Security in the 21st Century (3 weeks at Brookhaven National Laboratory); and the International Safeguards Pre-Inspector Course (2 weeks at Idaho National Laboratory). In July and August each summer, a NGSI HCD safeguards webinar series is broadcast to viewers twice weekly, featuring lectures on a wide range of safeguards and nonproliferation topics presented by safeguards experts from throughout the laboratory complex. Oak Ridge National Laboratory, Los Alamos National Laboratory, and Pacific Northwest National Laboratory hold short courses for students, interns, and professionals. NGSI HCD additionally co-sponsors the annual Public Policy and Nuclear Threats course held at the University of California- San Diego. Also in 2013, NGSI's oneweek safeguards course for members of the U.S. Government will take place over two days in Washington DC instead of five days at Lawrence Livermore National Laboratory, to give more DC participants the chance to attend. The annual week-long version of the course will resume in spring 2014.

\section{Professional Development}

The professional development component of NGSI's HCD program aims to engage early- and mid-career professionals in the safeguards field. Efforts such as speakers and seminars on international safeguards, access to training materials and courses, and involvement with NNSA-sponsored safeguards projects at the national labs are part of this initiative. NGSI is also sponsoring post-doctoral fellows at eight U.S. national laboratories. In 2011, this postgrad program was expanded to include post-masters fellows as well; this provides laboratories an avenue to retain accomplished interns once they graduate, and ensures that the "pipeline" of talent does not lose gifted post-graduates.

In 2009, Oak Ridge National Laboratory developed the concept of a Next Generation Safeguards Professional Network (NGSPN) to build connections between members of the next generation of safeguards experts. NGSPN held its inaugural meeting in October 2009, followed by training meetings at Savannah River National Lab (2010) and Pacific Northwest National Lab (2011). In October 2013, Los Alamos National Laboratory and Sandia National Laboratory will jointly host the fourth NGSPN meeting. The NGSPN initiative is particularly important in terms of retaining safeguards expertise, connecting young professionals who are new in the field, and developing awareness of safeguards competencies in the lab complex among the next generation.

\section{Knowledge Retention}


As safeguards specialists age and retire, it becomes increasingly important to ensure that the institutional knowledge such experts possess is not lost. With the support of NGSI HCD, a comprehensive project of filmed interviews took place in the first few years of the initiative, focusing on individuals who were involved in key nonproliferation events since the negotiation of the Nuclear Nonproliferation Treaty (NPT) in the late 1960s. These film series, entitled "Foundations of International Safeguards," have been published on DVD and web streaming.

In 2013, NGSI HCD is focusing more deliberately on knowledge retention issues. To address this issue head-on, the HCD program has undertaken a multi-year knowledge capture effort in collaboration with Oak Ridge National Laboratory and Brookhaven National Laboratory. This effort is directly focused on capturing institutional knowledge, and cataloguing, evaluating, and disseminating HCD-developed educational resources by providing a milestone for the program efforts thus far, and projecting training and demands for efforts in the future. The development of metrics will aid in determining where the state of nuclear education and training demands stand, as well as ascertaining what improvements must ensue to meet the educational demand for emergent experts.

\section{The Human Capital Development Roadmap Project}

The overall goal of this effort is to create a roadmap to determine future demand for expertise in the fields of safeguards and nonproliferation based on tangible metrics of current NGSI-sponsored programs at academic institutions and national laboratory facilities. A myriad of university, national laboratory, and government-sponsored programs have been offered, both domestically and globally, under the auspices of interdisciplinary safeguards and nonproliferation education. ${ }^{\text {iv }}$ However, the success of nuclear safeguards and nonproliferation education necessitates evaluation of infrastructure - intellectual infrastructure (expertise), academic and training program infrastructures, and physical and training facilities - in order to assess the efficacy of such programs overall in meeting NGSI training requirements. ${ }^{\mathrm{v}}$

The value of this project is not only as a measure of the physical and programmatic infrastructure in nuclear safeguards and nonproliferation traversing both academic and national laboratory institutions, but also in providing an assessment of the expertise pipeline in the core competency fields of nonproliferation and safeguards. The specialty fields within nonproliferation and safeguards are not monoliths, but contain various subject areas. Identification of these areas (ex. containment and surveillance, physical protection, NDA, DA, inspection) and the pipeline of knowledge and expertise in each primary field will ensure that the human capital pipeline is not nebulously filled with next generation safeguards experts, but appropriately targeted to ensure continuity of knowledge in critical fields. Although the aforementioned 2010 staffing study (undertaken and completed by ORISE on behalf of NGSI) attempts to delineate human capital personnel in the fields of nonproliferation and safeguards, it does not make proactive measures to assess existent educational and training programs, training facilities and infrastructure, and domestic and international demand in specific subject areas within nonproliferation and safeguards.vi Where the study conducts a "back-end" assessment of demand, this Roadmap study conducts a "front-end" assessment of supply based on tangible metrics of current NGSIsponsored programs at academic institutions and national laboratory facilities. 
Based on the data obtained from NGSI-sponsored academic courses, in tandem with the development of practical training and infrastructure at national laboratories, metrics for recruitment and retention in safeguards and nonproliferation are being made, correlating end-to-end efforts for NGSI training. In addition to domestic expertise development, the demand for training and support on an international level will be assessed in future activities, as will future training demands from domestic and international entities. The Roadmap will bridge the recruitment/retention aspects with the demand aspects articulated in the 2010 staffing study, and further qualify program successes and identify gaps.

\section{Objectives and Methodology}

The specific objectives of this new effort two-fold:

(1) To provide recruitment/retention metrics to determine where the state of nuclear education and training demands stand, as well as to determine what improvements must ensue to meet the educational demand for emergent experts; and

(2) Establish a formal means by which knowledge retention activities can occur, transferring knowledge from outgoing safeguards experts to incoming generations.

\section{(1) Development of Metrics}

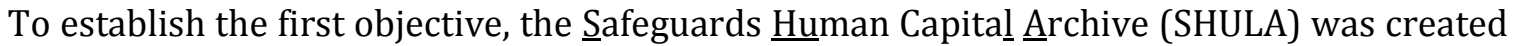
to couple with extensive survey acquisition tools. This platform was populated with historic data regarding NGSI HCD participants from past short courses, internships, and other HCDsupported activities. To streamline acquisition of complete data of all NGSI-HCD participants in supported programs, surveys were created and distributed, initially in hardcopy format. These survey forms are currently being transitioned into electronic format through the use of advanced survey data acquisition web-based software.

Three types of surveys have been created for the following HCD-sponsored-activity participants:

- University Semester Course - Student

- Short Course - Student

- Short Course - Professional

Initial data from the collected surveys has provided, and will continue to provide, valuable guidance for future NGSI HCD efforts. Some of the preliminary feedback includes the following:

- Mid-career training: There was an ever present desire in the professional groups for mid-career training opportunities. When looking at the four short courses with the broadest participant reach, 1 three are targeted primarily at graduate-level students or early professionals. More advanced curriculum training opportunities are recommended to build upon introductory courses.

\footnotetext{
${ }^{1}$ NNSS (BNL), ISPIA (LLNL/MIIS), PPNT (UCSD), and INL's course - see section on short courses
} 
- Appropriate target level for courses: In order to accommodate the need of the safeguards community, there is a need for adjustments and growth of the programs. 61 percent of the professionals who are involved with engineering or other technical roles identified that Master's-level students, as well as early career professionals, should be the main targets for safeguards education.

- Mentorship: Many suggestions for mentorship programs expressed the need to retain valuable information in order to fill future gaps that will occur when members of the community leave the workforce. Mentorship is seen as a retention method particularly to those who have gone through previous introductory safeguards courses and wanted to pursue higher-level training and education.

- Advertisement of NGSI HCD opportunities: Venues for recruitment and retention for NGSI HCD include various professional societies. In all of the studies, over half of the participants were members of some society with a large number of those involved in the ANS, INMM, and HPS.

- Continued interest in the field: In the courses polled thus far, it is evident that there is strong interest from students and professionals wishing to learn more about safeguards and nonproliferation. Those who were unaware or uninterested prior to their participation in the courses showed that their interest increased and all groups showed that the majority would be likely to pursue a career in safeguards. Furthermore, a broad spectrum of disciplines and majors were present in the courses, which helps to address the core capabilities that the international safeguards community wishes to maintain.

\section{(2) Knowledge Capture Activities}

The untimely passing of Trond Bjornard of Idaho National Laboratory, as well as the mass retirements of current experts, highlight the importance of archiving knowledge in the highly specialized fields of safeguards and nonproliferation work. Identifying subjectmatter experts across the Department of Energy (DOE) complex at national laboratories and meeting to interview with them in a "knowledge capture" exercise will provide a cohesive insight into the pipeline of specialists that must continue in these specialized fields. Complementary to the identification of national laboratory infrastructure, this task is intended to capture the "intellectual infrastructure." Subject-matter experts will be interviewed specific to perspectives on the demands of next generation safeguards work. An elaboration of the knowledge capture paradigm will occur through the following four activities:

1. Framework design of the SHULA database: Investigate methods for knowledge capture efforts with other those of other industries and agencies located domestically and internationally to retain knowledge in the nuclear field; concept mapping, differentiation between tacit, implicit and explicit knowledge capture techniques; and identification of major subject matter areas (professional society, conferences, publications). During this effort, HCD efforts of other organizations and agencies, both in and outside government, will be compared with that of NGSI.

2. Knowledge capture of subject matter: Identification and archival of NGSI HCDsponsored publications, technical and policy projects, and syllabi and training material). 
3. Knowledge capture from subject matter experts to capture "intellectual infrastructure": Subject-matter experts will be interviewed specific to next generation safeguards work in interviews reminiscent of the previous "Foundations of International Safeguards" media effort.

\section{Conclusion}

The implications of this ongoing Roadmap project are of value not only to NGSI but also the wider safeguards community. Many young professionals find their way into U.S. national labs, the IAEA, or the U.S. Government via the pipeline created by the HCD program. This roadmap will holistically analyze the education, training, and knowledge retention of these programs to identify if future demands meet present goals.

The high numbers of NGSI alumni continuing in the safeguards/nonproliferation field is encouraging. Many of the university students who have participated in NGSI programs have further orientated (or in some cases re-oriented) their studies towards safeguards and nonproliferation. Students in nuclear engineering and other technical or science fields have stated that before safeguards exposure under NGSI they were not aware of the professional opportunities that exist in the safeguards field. vii

In the immediate future, NGSI will continue to address the imbalance between the demand for safeguards human capital and its supply, with a goal of supporting and strengthening the international nuclear nonproliferation regime. NGSI HCD will also continue to seek opportunities to collaborate with and/or support safeguards international engagement efforts. The 2013 update to the safeguards workforce staffing study, and in particular the Human Capital Development Roadmap project outlined in this paper, are important next steps in ensuring NGSI is offering a tailored and right-sized approach to the ongoing human capital challenge. Through NGSI, NNSA will continue to establish a human capital development system that seeks to staff international safeguards positions at the national laboratories, federal agencies, and at the IAEA Department of Safeguards with qualified U.S. candidates.

\footnotetext{
iM. Scholz, "Next Generation Safeguards Initiative Human Capital Development Program," NGSI International Engagement Program Review, Washington, DC, 2013.

ii Scheinman, Adam "Calling for Action: the Next Generation Safeguards Initiative." Nonproliferation Review, Vol. 16, No. 2. July 2009.

iii NNSA Office of Nonproliferation and International Security. "International Safeguards: Challenges and Opportunities for the 21 $1^{\text {st }}$ Century." October 2007.

iv K. Gilligan, "Safeguards Professional Development Opportunities," in Proc. IAEA Symposium on International Safguards, Pittsburgh, PA, 2010.

v S. A. Dewji, N.E. Hertel, "Benchmarking Safeguards and Nonproliferation Education: A Heuristic Approach," American Nuclear Society National Meeting, Hollywood, FL, 2011.

viL. Blair, D. Johnson, "Nuclear Nonproliferation International Safeguards Scientist and Engineer Workforce at U.S. Department of Energy National Laboratories", Nuclear Security Education: The Intersection of Policy, Science, and Technology Workshop, Knoxville, TN, 2010.
} 
http://wiki.ornl.gov/sites/gnstd/gssec/meeting4/Documents/PRESENTATIONS/Blair_Tue_7-20ORISE.pdf

vii “Next Generation Safeguards Initiative: Human Capital Development Program." Fiscal Year 2009 Annual Report. October 2009. 